\title{
The laws of niddah as a means of controlling female sexuality
}

\begin{abstract}
This article presents how the laws of Niddah in Judaism are influenced by the cultural attitude to menstruation and how the cultural attitude to menstruation is related to the social status of women. The laws of Niddah are consider in historical and contemporary perspective with special interests in attitudes to women menstruation and sexuality. The social and biological domain are analyzed to understand the connections between power struggles and behavior regulations.
\end{abstract}

Keywords: gender studies, Judaism, menstruation

ince the dawn of history in primitive cultures, different kinds of beliefs, powers, $\checkmark$ and magic were attributed to women's menstruation. Researchers have studied the similarity and connection between different societies regarding menstruation. Menstruation is defined as unclean and dirty and menstruating women were considered dangerous and were removed from their homes during menstruation.

In ancient societies in the past and in some tribes in Africa today, menstruating women are deported to the "Red Tent." It was Aristotle who claimed that the blood of a woman, whose color is red, was less pure than the white sperm of the man.

In her book "Purity and Danger,"1 anthropologist Mary Douglas analyzed cultural phenomena dealing with impurity and danger. According to Douglas, people are deterred by what they label as dirty or impure, because they interfere with the order through which they organize their lives.

\footnotetext{
${ }^{1}$ M. Douglas, Purity and Danger (remake) Resling Publishing, 2002.
} 
As part of the explanation for The deterrence from menstruation, Douglas quotes anthropologist Levi-Bruhl, who noted that in certain cultures menstrual blood was considered to be a type of a human being. For if it did not have left the body, it would have become a fetus. Therefore, menstruation blood has the status of a dead person who has never been born and is considered to be dangerous. It seems that this is also part of the explanation for mystical powers attributed to menstrual blood.

Julia Kristeva, ${ }^{2}$ who studied the universal social relation to menstruation from a feminist point of view, continued Douglas's ideas and argued that according to the psychoanalytic approach the role of "impurity" renders menstrual blood a rejected thing, which lies Behind the fear of the woman's desire.

The ideas according to which the universal relation to menstruation is social, and the analysis of the laws of niddah is carried out according to the set of social forces is also detailed in the book of the anthropologist Nissan Rubin. ${ }^{3}$

Rubin describes the lack of social stability in a woman's life when she leaves her father's house for her husband's house. The lack of social stability, in his opinion, should be added to the lack of biological stability, between fertility and infertility. During the fertility period the woman is pure and part of her husband's family and considered "inside," with a role in the social system. She is "worthy" to conceive; in times when she is not fertile she is unclean and considered "outside" \& "Unworthy." The laws of niddah, according to Rubin, symbolize the social status of women, which is boundless by fixed and clear boundaries, and borders are blurred. When every month a woman crosses the boundaries between purity and impurity back and forth.

\section{Menstruation in Judaism}

In Judaism and Islam there are remnants of ideas that were common in the ancient period according to which women, during the menstrual period, are attributed to the forces of impurity and magic and surrounded by demons and spirits, and through them can do harm to those around. ${ }^{4}$ That's why in medieval Jewish rabbinical literature, women during menstruation were removed from society and prohibited from many activities, including cooking, baking, praying, entering cemeteries and more. all that including of course the prohibition of engaging in sex. These many prohibitions and rules were combined and edited into what is known as the "Nida rules."

Many Jewish scholars and rabbis discussed the Nida rules during the ages and today we can typify the Nida rules into two main categories: the first emphasizes

2 J. Kristeva, The Powers of Horror A Treatise on Despair, Rastling Publishing, 1980.

${ }^{3}$ N. Rubin, The Beginning of Life, Hakibbutz Hameuchad, Ra'anana 2005.

${ }^{4}$ T. Canaan, One Constitution and One Law for Man and Woman, in M. Shilo, E. Katban, R. Halperin-Kaddari (eds), Women, Rights and Justice during the Mandate, Bar-Ilan University Press, 2010. 
the impurity and the other narrows down the prohibitions only to regulating the sexual relations.

Today the religious prohibitions regard mainly the sexual relations in relation to the purity or impurity. The woman will become pure only after immersing in the Mikva, at the end of all stages of Nida. After all that the couple will be able to engage in sexual relations.

The discussion between purity and impurity includes various laws concerning various topics such as counting the clean days, the time of immersion, the purification tests and the baptism itself, each of which can invalidate baptism and consequently leave the woman unclean and the male is forbidden to have sex with her. ${ }^{5}$ The prohibition applies mainly to married couples (since it is not necessary to have sex outside marriage) and the woman is forbidden to her husband during this period. In fact, until the woman has immersed herself in the Mikvah, after completing all the other stages, she will remain impure. The men are warned that anyone who violates the prohibition on having sexual relations with an impure woman will be treated as a "karet," one of the gravest laws in Judaism. Women are also warned that violating the laws of niddah is one of the reasons why they die during childbirth and give birth to a baby with fetal defects.

\section{Nida as a power field}

Rubin, in his book, quotes from the Bible comparing the status of sexual intercourse with a niddah woman, as incestuous, and therefore, we see, to his understanding, how severe is the prohibition of sleeping with a niddah woman. He explains that the difference between the universal social attitude similar to Douglas's cross-cultural work, the various body secretions, the deceitful and the ordinary, lies in the ability to control them. The ability to control the secretions, even goes beyond the boundaries of biology and dictates the social order, the one with the power to control his secretions gets the right to dictate the social order.

The idea of control over secretions dates back even to the time of Plato who stated that the woman was inferior, because the height of spirituality \& intellect is to ascend over the body and women haven't succeeded in doing so to control their menstruation.

In the article Nida and Nationality: The Woman's Body as Text, ${ }^{6}$ Rappaport and Yanai analyze the duties of "family purity." The new name given to the laws of niddah, which may also imply that this is not a purely biological or halachaic

${ }^{5}$ A. Pikar, The Philosophy of Rabbi Ovadia Yosef in an Era of Changes: Halachic Research and Cultural Criticism, Bar-Ilan University Press, 2006.

${ }^{6}$ N. Yanai, T. Rapoport, Nida and Nationalism, The Woman's Body as Text, Will you hear my voice? Representations of Women in Israeli Culture, The Lear Institute Jerusalem, 2001. 
issue). In the article they map the six sets of rules, that women are required to observe during menstruation:

- Rules relating to the woman's abstention from sexual relations and from any contact with her husband.

- Rules regarding stain testing.

- Rules regarding purity tests.

- Rules for clean days.

- Rules regarding preparation for ritual immersion.

- Rules regarding immersion in the mikvah itself.

However, Yanai and Rapaport point out that although there are seemingly very clear rules regarding each stage of purification, and although there are many halakhic rulings and the entire field is multi-discourse, the rules are still very vague and the authority to rule whether or not the woman is pure is reserved for the rabbi. This ambiguity perpetuates the power to judge whether a woman is pure or impure by men. The rabbi is the supreme authority that determines whether the woman is pure or impure.

Further reinforcement of the fact that the laws of niddah preserve the superiority of men and that they are cultural rather than biological, can be found in the laws related to niddah after birth. After the birth of a daughter and the birth of a woman's son is niddah, but since this is not menstrual blood but rather blood for birth, the woman is in a seam between impurity and purity.

Since a woman may breastfeed for a period of months, the woman is given the opportunity to be purified by circumcision, blood that cannot be controlled with controlled blood (Rubin). That's why in the birth of a son, she is impure for only a week and after that she will be in a intermediate status for 33 More days, but will not be completely impure. Whereas in the birth of a daughter, for whom no circumcision ceremony was held, the woman would be unclean for two weeks and in an intermediate state for 66 days.

In other words, despite the fact that in biology there is no difference between the birth of a daughter and the birth of a son, the woman is "punished" for the birth of a daughter and even if the woman is menstruated during her purifying days and seemingly halachically, she can immerse and no longer be impure, the social definition is stronger than the biological one and she still is defined as impure.

\section{Women's struggle for independence}

In recent years, as women have progressed, women have begun to acquire knowledge, including halachic knowledge, and sought to gain control over the field of supervision of the laws of niddah. The rabbinical establishment objected strongly. Rabbi Ovadia Yosef, who was considered the greatest of the Sephardi rabbis (Ariel 
Picard), also called for the expropriation of control from women, even from women with Torah training.

In 2015, women who wished to immerse themselves in a ritual bath (the Mikvah) petitioned to the High Court of Justice for performing the ritual without the supervision of the "Balanit" (a woman authorized by the religious council to ensure that the ritual bath was performed legally). Since that petition, they were authorized to do so without a "balanit."

The religious council objected and claimed that religious baptism would be unacceptable and that unacceptable baptisms could not be allowed. The Supreme Court ruled that a woman who is not interested in the presence of a "balanit" can request to be immersed alone and must be allowed to do so. The petition to the supreme court regarding the Mikvaot supervision, marks the recent trend and objection of religious women against the traditional Nida rules and how they are still implemented today.

In a qualitative study conducted by Tanya Chipman ${ }^{7}$ with religious women who experienced sexual abuse, she describes the difficulty in the testing ritual, immersion and afterwards in social expectation in having sex on the day of baptism, when a woman can hardly refuse. In an article presented at the International Conference "Woman and Judaism," quotations of the women interviewed are presented. One woman claimed, "I hate the mikvah. This situation in which she examines me, looks at my body, when I am bare and naked - it is so shameful. Scary ... I can not go there alone."

The feminine call for change in the practice of the laws of niddah went beyond the boundaries of academia, and assumed a place of honor in Israeli society. For example, Ruchama Weiss, who is a lecturer and researcher of Talmud, has published articles on the laws of niddah and male domination of the woman's body through the laws of niddah in a leading news site. ${ }^{8}$ Women began to publish art from menstrual blood to challenge The alleged impurity. ${ }^{9}$ In the past, it was reported that women who refused to have sexual relations with their husbands, women who wanted to immerse themselves in the day because it was customary to immerse in the night after sunset and even broke the gates of the mikveh in Baghdad in the $12^{\text {th }}$ century and women who insisted on bathing after a week in Egypt during the period of Rambam (1138-1204), instead of after at least 12 days. All these protests

7 T. Chipman, Women and Judaism: A Contemporary Feminist-Religious Discourse: A Selection of Lectures from the Sixth and Seventh International Conferences A Woman and Judaism, Tova Cohen, Reuven Mass Publishing Ltd., Jerusalem 2013.

${ }^{8}$ R. Weiss (n.d.), A Male Regime on the Woman's Body, https://www.ynet.co.il/ articles/0,7340,L-4648123,00 [22.12.2018].

${ }_{9}$ R. Tzaraf, Beyond Bazes, Moved in Contemporary Art, Gender-Halakhic Discussion, BenGurion University, 2017.10; I..E. Sikorl, N. Zilman, Borders in Blood: Case Studies of Women, in E. Ginsberg (eds), Nida Practices, A Study of the Cycle of Studies in Menstruation in Israel, pp. 19-55, Sapir Forum for Cultural Research and Study, 2017. 
remained a weak response, and at the end of the day the women returned under rabbinical supervision.

Today, in the age of the Internet, women have access to halachic knowledge and are practicing their own law. Is the fact, that knowledge is accessible, cause a real revolution and return power to women?

In an article by Cicurel \& Zilman, they analyze the field of power between men and women ${ }^{10}$ through the laws of niddah, when according to them, women have a lot of power when the rabbi relies on their reports.

In conclusion, as we have seen, the laws of niddah are a social domain and not merely a halachic biological one. An area in which power struggles and behavior regulation are expressed. The discourse of purity versus impurity, contains an element of supervision, when those in possession of supervision, will control. Today the supervisor is a man and not a woman, hence control is given to men. Even though we see a growing trend of attempts to transfer control to the hands of women.

\section{Literature}

Chipman T., Women and Judaism: A Contemporary Feminist-Religious Discourse: A Selection of Lectures from the Sixth and Seventh International Conferences A Woman and Judaism, Tova Cohen, Reuven Mass Publishing Ltd., Jerusalem 2013.

Canaan, T., One Constitution and One Law for Man and Woman, in M. Shilo, E. Katban, R. Halperin-Kaddari (eds), Women, Rights and Justice during the Mandate, Bar-Ilan University Press 2010.

Douglas M., Purity and Danger: An analysis of concepts of pollution and taboo. Sociology. https://doi.org/10.1177/003803856700100211, 1967.

Kristeva J. (1982). Powers of Horror: An Essay on Abjection. New York, https://doi. org/10.1016/S2222-1808(15)60863-5

Pikar A.. The Doctrine of Rabbi Ovadia Yosef in an Era of Change: The Study of Halakhah and Cultural Criticism, Bar - Ilan University, 2007.

Rubin N. The Beginning of Life, Hakibbutz Hameuchad, Ra’anana 2005.

Sikorl I..E. \& Zilman, N., Borders in Blood: Case Studies of Women, in E. Ginsberg (eds), Nida Practices, A Study of the Cycle of Studies in Menstruation in Israel, Sapir Forum for Cultural Research and Study, 2017.

Tzaraf R., Beyond degrade gender discourse in the art of menstruation, Gender-Halakhic Discussion, Ben-Gurion University, 2017.

Yanai N., Reformport, T., Nida and nationalism, the woman's body as text, Will you hear my voice? Representations of Women in Israeli Culture, The Lear Institute, 2001.

Weiss R. (n.d.). A Male Regime on the Woman's Body; https://www.ynet.co.il/article$\mathrm{s} / 0,7340, \mathrm{~L}-4648123,00$

${ }^{10}$ I.E. Sikorl, N. Zilman, Borders in Blood: Case Studies of Women, in E. Ginsberg (eds), Nida Practices..., pp. 19-55, Sapir Forum for Cultural Research and Study, 2017. 